\title{
Nalmefene Hydrochloride
}

National Cancer Institute

\section{Source}

National Cancer Institute. Nalmefene Hydrochloride. NCI Thesaurus. Code C47631.

The hydrochloride salt form of nalmefene, a naltrexone analogue with opioid antagonistic property. Nalmefene antagonizes the effects of opioids by competing for the opioid receptors in the CNS. This results in reversal of the effects of the opioids, including reversal of analgesia, euphoria, respiratory depression, hypotension, sedation and physical dependence. 